\title{
An extensive burden of giardiasis associated with intestinal schistosomiasis and anaemia in school children on the shoreline of Lake Albert, Uganda
}

Hajri Al-Shehria ${ }^{\mathrm{a} b}$, Michelle C. Stanton ${ }^{\mathrm{b}}$, James E. LaCourse ${ }^{\mathrm{b}}$, Aaron Atuhaire ${ }^{\mathrm{c}}$, Moses Arinaitwe ${ }^{\mathrm{c}}$, Aida Wamboko ${ }^{c}$, Moses Adriko ${ }^{c}$, Narcis B. Kabatereine ${ }^{\text {c,d }} \&$ J. Russell Stothard ${ }^{\text {,** }}$

${ }^{a}$ Department of Parasitology, Liverpool School of Tropical Medicine, Liverpool, L3 5QA UK; ${ }^{\mathrm{b}}$

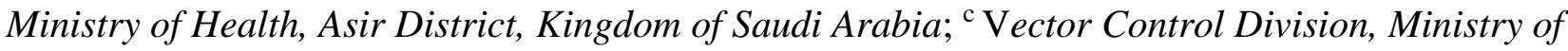
Health, Kampala, Uganda; ${ }^{d}$ Schistosomiasis Control Initiative, School of Public Health, Imperial College London, London W2 1PG, UK

* Corresponding author. Tel: +44 (151) 705 3724. E-mail: russell.stothard@1stmed.ac.uk 


\begin{abstract}
Background: Water-borne parasitic diseases associated with poverty still blight the lives of African school children. In Uganda, intestinal schistosomiasis is still common along the shoreline of Lake Albert, despite ongoing control, and co-infection with giardiasis and malaria is poorly known. To shed light on putative interactions between diseases, a prospective cross-sectional parasitological survey was undertaken across 5 primary schools.
\end{abstract}

Methods: Stool samples from total of 254 school children, aged 5-10 years, were examined by microscopy and rapid diagnostic tests (RDTs), with additional real-time PCR assays for detection of Giardia DNA. A finger-prick blood sample was also taken from each child and tested for malaria and haemoblobin levels measured. Assocations between diseases and anaemia were assessed.

Results: Intestinal schistosomiasis (46.5\%), giardiasis (41.6\%) and malaria (56.2\%) were common, and a quarter of children were anaemic $(<115 \mathrm{~g} / \mathrm{L})$. Up to $87.0 \%$ of children were excreting Giardia DNA and the prevalence of heavy infection by real-time PCR $(\mathrm{Ct} \leq 19)$ was $19.5 \%$, being positively associated with light, moderate and heavy egg-patent schistosomiasis, as well as, with anaemia.

Conclusion: In this setting, an extensive burden of giardiasis was revealed with heavy intensity infections associated with egg-patent intestinal schistosomiasis and anaemia. To improve child health, greater attention on giardiasis is needed along with exploring joined-up actions across diseases that promote better water hygiene and sanitation measures.

Keywords: Schistosoma, Giardia, Plasmodium, epidemiology, co-infection, control 


\section{Introduction}

In impoverished regions of sub-Saharan Africa water-borne parasitic diseases in addition to malaria pose a significant threat to the well-being of children. In parts of Uganda, for example, intestinal schistosomiasis is hyper-endemic along the shorelines of the Great Lakes and is particularly rife around Lake Albert ${ }^{1-3}$. Local aetiological factors include favourable freshwater snail habitats, poor local sanitation and hygiene, as well as, extensive levels of daily water contact by shoreline communities ${ }^{4-}$ ${ }^{6}$. While an extensive burden of malaria is known ${ }^{7-10}$, the occurrence and extent of another waterborne, poverty-related disease, giardiasis, has yet to be investigated. In 2003, a national control programme against schistosomiasis and intestinal worms was launched at Pakwach (see Figure 1$)^{11}$. Since then there have been substantive actions to deliver praziquantel and albendazole by mass drug administration (MDA) to at-risk children attending primary schools and adults in endemic areas ${ }^{2}$. Owing to high levels of re-infection ${ }^{12}$, an extensive burden of intestinal schistosomiasis remains and children with hepatosplenic and gastrointestinal disease can be found ${ }^{13}$

Giardiasis is caused by Giardia spp., a binucleate flagellated protozoan, and is associated with ingestion of infectious cysts on foods or in drinking water, as contaminated by faecal waste from humans and(or) animals carrying patent or cryptic infections ${ }^{14,15}$. In low and middle income countries, prevalence of human giardiasis can vary widely, typically from 0-30\%, and depending on which diagnostic is applied, can be almost universal in certain populations ${ }^{16,17}$. Although infections with Giardia spp. may be acute and self-limiting, chronic disease, such as persistent diarrhoea, leads to malabsorption and weight $\operatorname{loss}^{18}$. Co-infection with other poverty-related diseases, such as soiltransmitted helminthiasis occurs, and with ascariasis, immunomodulation of the gut mucosal surface favours chronic giardiasis ${ }^{19,20}$. Across Uganda, formal reporting and surveillance of giardiasis is very scant ${ }^{21-23}$. While the disease is zoonotic in livestock and an important anthropozoonosis of the mountain gorilla $\mathrm{a}^{24,25}$, the burden of giardiasis in school children is largely unknown, as are any associations with intestinal schistosomiasis.

The aim of this present investigation was to conduct a prospective cross-sectional parasitological survey to ascertain current levels of intestinal schistosomiasis, giardiasis and malaria among schoolchildren (5-10 years of age) on the shoreline of Lake Albert, Uganda. Associations between diseases were assessed and as three of the five schools first surveyed for intestinal schistosomiasis in 2002-2003, a comparison through time was made.

<insert Figure 1 near here please> 


\section{Materials and methods}

\section{Study location}

In June 2015 in Buliisa District, Western Uganda, a prospective cross-sectional parasitological survey, using parasitological methods augmented with rapid diagnostic tests (RDTs), was undertaken across 5 primary schools. Three schools were selected on the basis that a baseline assessment had been undertaken in 2002-2003 and historical data were available from: Biiso (GPS co-ordinates: $01^{\circ} 45.516$ $\left.\mathrm{N}, 031^{\circ} 25.236 \mathrm{E}\right)$, Walakuba (GPS $\left.01^{\circ} 50.323 \mathrm{~N} 031^{\circ} 22.740 \mathrm{E}\right)$ and Runga (GPS $01^{\circ} 43.828 \mathrm{~N} 031^{\circ}$ $18.603 \mathrm{E})(26,27)$. Two additional schools were selected Bugoigo $\left(01^{\circ} 54.004 \mathrm{~N} 031^{\circ} 24.750 \mathrm{E}\right)$ and Busingiro (GPS $01^{\circ} 44.090 \mathrm{~N} 031^{\circ} 26.855 \mathrm{E}$ ) on the basis that the former school was sited very close to the shoreline while the latter school was furthest away from lake ( $\sim 25$ kilometres). Busingiro was accessible on a daily basis from Bugoigo, where the field team was encamped, and intestinal schistosomiasis was presumed to be minimal there allowing associations between diseases in the putative absence of Schistosoma mansoni to be assessed (see Figure 1).

\section{Examination of children}

In liason with the headmaster and class teachers, a pre-target enrollment of 60 children per school, of balanced gender, randomly recuited from classes primary 1 to 3 , was performed. A finger-prick blood was collected from each child and tested for malaria by RDT (SD BIOLINE Malaria Ag P.f/Pan test, SD Diagnostics, Korea) and haemoglobin levels by HemoCue ${ }^{\circledR}$ portable hemoglobin photometer (HemoCue, CA 92630, USA). Children were considered anaemic if haemoglobin levels were below $115 \mathrm{~g} / \mathrm{L}^{28}$.

\section{Examination of stool specimens}

Each child was requested to provide a stool sample on two consecutive days. All stool samples received on the first day were tested for faecal occult blood (FOB) (Mission Test, Acon Laboratories, SanDiego, CA). In Bugoigo and Runga schools, all children were tested with Quik-Chek tests for Giardia and Cryptosporidium (GIARDIA/CRYPTOSPORIDIUM QUIK-CHEK, Alere, UK). The Quik-Chek RDT is typically used to measure clinically relevant giardiasis with a level of detection of 6000 cysts/ml of faeces. Owing to a limited supply of 100 Quick-Check tests alone, only children from these two schools were tested while a more general detection of giardiasis was undertaken by recourse to real-time PCR assays. Duplicate faecal smears were prepared from each stool sample from consecutive days using Kato-Katz thick smear technique $(41.7 \mathrm{mg}$ ) and examined by compound light microscopy 
and helminth egg tallies were recorded according to eggs per gram of stool (light 1-99, medium 100399, heavy 400+). A later $10 \%$ re-read of slides was performed as quality control. After filtration through a metal mesh $(212 \mu \mathrm{m}$ pore size), small faecal pellet-sized sample from each child was preserved in absolute ethanol for later DNA extraction and real-time PCR analysis.

\section{Real-time PCR analysis}

After transfer to the UK and each sample was spiked with Phocine Herpes Virus to act as an internal control for extraction and performance of real-time PCR assays. Genomic DNA was extracted and detection of Giardia DNA was performed using the Taqman ${ }^{\circledR}$ assay following primer, probes and protocols of Verweij et al. ${ }^{29}$. Assays were performed in a Chromo-4 with Opticon monitor ${ }^{\mathrm{TM}}$ Version 3.1. (Biorad, UK) and levels of infection categorised according to $\mathrm{Ct}$ values: no infection $(\mathrm{Ct} \geq 40)$, light $(30 \leq \mathrm{Ct} \leq 39)$, moderate $(20 \leq \mathrm{Ct} \leq 29)$, and heavy $(\mathrm{Ct} \leq 19)$ intensity infections ${ }^{29}$.

\section{Statistical analysis}

All data collected in the field were recorded on pro-forma data sheets then tabulated in Microsoft Excel with double entry cross-check. Analysis was performed with R statistical package v $2 \cdot 10 \cdot 1$ (The R Foundation for Statistical Computing, Vienna, Austria) and SPSS software (v 24.0, SPSS Inc., IBM, USA). For percentage values, $95 \%$ confidence intervals $\left(\mathrm{CI}_{95}\right)$ were estimated using the exact method (30). With an extensive burden of giardiasis revealed by real-time PCR, greater focus was placed on exploring association of heavy infections with Giardia inclusive of: gender, age, anaemia and infection intensity of other parasitic diseases. A univariate logistic regression analysis was performed to study the association between infection status and the risk factors under consideration. The level of significance of $p<0.05$ was set for multivariable analysis; the model was interpreted using adjusted ORs and 95\% CIs. The prevalence of intestinal schistosomiasis at Runga, Walakuba and Biiso between 2002 and 2015 was compared by a 1-tailed Z-test ${ }^{30}$.

\section{Ethical approval}

The Ugandan Council for Science and Technology and the Liverpool School of Tropical Medicine granted approval for this study. Each child was examined by the project nurse (AA) and praziquantel (40 mg/Kg, Merck, Germany) and albendazole (400 mg, GSK, UK) treatment was administered to all participants irrespective of their infection status. Children with a positive malaria RDT were each offered a take-home, 3-day course of coartem (Lonart®, Cipla, India) with the first and third administrations directly overseen by the project nurse. 


\section{Results}

\section{General characteristics}

A total of 274 children were originally recruited, however, owing to instances of failure to produce stool, a final data set was composed of 255 children, mean age of 6.8 years $(95 \% \mathrm{CI}=6.6,6.9)$ with a balanced male $(49.4 \%)$ to female $(50.5 \%)$ ratio.

<insert Table 1 near here please>

\section{Prevalence of disease}

Table 1 illustrates the prevalence of infection across the five schools, egg-patent intestinal schistosomiasis of $46.5 \%$, giardiasis and malaria by RDT of $41.6 \%$ and $56.2 \%$, respectively. The prevalence of egg-patent intestinal schistosomiasis at Walakuba and Runga was $82.0 \%$ and $86.8 \%$, with the majority of children having heavy intensity infections. Overall, prevalence of Giardia by RDT was $41.6 \%$ but by real-time PCR increased to $87.9 \%$ which was graded into light (27.6\%), medium $(40.8 \%)$ and heavy $(19.5 \%)$ categories upon comparison with $\mathrm{Ct}$ values. Just over half of the children were positive for malaria by RDT, with triple co-infection, in just under a fifth of the population. A quarter of children were judged anaemic and FOB was found in $11.0 \%$ of stool samples.

<insert Table 2 near here please>

\section{Associations with giardiasis}

Factors potentially associated with the presence of heavy Giardia infection as ascertained by real-time PCR were analysed are shown in Table 2. The prevalence of heavy Giardia infection was strongly associated with Runga school [OR, 5.7 (95\% CI, 2.18-17.0)] while both age and gender had no a noticeable impact. The positive association [OR, $2.3(95 \% \mathrm{CI}, 0.89,5.1)]$ with faecal occult blood (FOB) was marginal but all egg-patent intestinal schistosomiasis infection intensities were positively associated some 3 to 4 fold. There was a significant association between anaemic children and heavy giardiasis [OR, 2.2 (95\%CI, 1.41,4.3)], Figure 2.

<insert Figure 2 near here please>

\section{Intestinal schistosomiasis through time}

In 2002, the prevalence and the arithmetic mean intensity of children with intestinal schistostosomiasis at Runga, Walakuba and Biiso in 2002 versus 2015 was 95.2\% (631 epg) v 86.7\% (1723 epg), 90.4\% 
(1026 epg) $v 80.3 \%$ (814 epg) and 17.2\% (52 epg) v 19.6\% 198 (epg) respectively. The declines (approximately 10\%) in prevalence at Runga and Walakuba were statistically significant $(\mathrm{p}<0.05)$ while the small incline at Biiso was not $(\mathrm{p}>0.3)$.

\section{Discussion}

In this survey across 5 primary schools, an extensive burden of parasitic diseases, inclusive of coinfections, has been revealed, see Table 1. Triple infections of intestinal schistosomaisis, giardiasis and malaria affected just under a fifth of all sampled children. Although all were sufficiently fit to attend school, more general markers of ill-health, such as anaemia $(25.7 \%)$ and faecal occult blood $(11.0 \%)$, revealed an underlying morbidity, as previously seen in this area ${ }^{31,32}$. Along the lakeshore, access to tap water is still very poor which no doubt helps both intestinal schistosomiasis and giardiasis flourish ${ }^{17,33-35}$. Moreover, a concurrent malacological survey of the shoreline was undertaken and found numerous snails shedding schistosome cercariae ${ }^{36}$, as several times before ${ }^{5,37}$. Clearly, there is a pressing need to establish and sustain safe water sources for both drinking and washing on the immediate shoreline as a foundation step towards promoting well-being ${ }^{38}$.

The burden of intestinal schistosomiasis appears greatest at Runga and Walakuba schools, as it once was upon comparison with other locations along this lake $\mathrm{e}^{26,27}$. Despite best efforts of control with school-based delivery by MDA of praziquantel, the resultant declines in egg-patent prevalence $(\sim 10 \%)$ were small although statistically significant. Whilst this is movement in the right direction, rather worryingly, there were large numbers of children with heavy intensity infections, Table 1. Looking to the future, a more aggressive treatment strategy is needed gain and sustain control, such as exploring biannual treatment cycles in both children and adults, as well as, tackling the burden of infection in preschool-aged children ${ }^{36,39}$.

The pervasive nature of giardiasis in this lakeshore setting is of concern and warrants greater attention in future. Use of the Quik-Chek RDT revealed that, whilst no cryptosporidiosis was encountered, a considerable number of children at Runga and Bugoigo were patently infected with clinically relevant Giardia. This was later confirmed by real-time PCR which, by having greater diagnostic sensitivity ${ }^{29}, 40-42$, found a larger proportion of children with some evidence of infection. This points towards very high levels of exposure perhaps by the daily ingestion of cysts from lake water from unsafe water sources.

Whilst there was a strong association of heavy Giardia infection and egg-patent intestinal schistosomiasis its precise aetiology is yet to be determined. It is reasonable to speculate that egg- 
induced lesions, which perforate and immunomodulate the mucosal surface ${ }^{31}$, likely alter the bowel environment to become more conducive for colonisation of ingested Giardia cysts. Similarly, while it is difficult to disentangle precisely the relative role each disease is playing in the current context of intestinal morbidity, there was a clear association of heavy giardiasis with anaemia [OR, 2.2 (95\%CI, 1.41,4.39)]. Amongst other causual factors, this could be due to underlying nutritional deficiencies, mediated by general intestinal inflammation, inclusive of chronic blood loss by faecal occult blood ${ }^{9}$. 32. Nevertheless, if anaemia is to be tackled effectively here, from a public health perspective it is important to tackle all three diseases as best possible simultaneously.

Acknowledgments: We extend sincere thanks to the school children, teachers, districts officials and the population around Lakes Albert in Buliisa District, Uganda for their participation and assistance in conducting the field-work. We are grateful to Dr Jaco Verweij for sharing his technical knowledge and laboratory support.

Authors' contributions: HAl-S, JRS, NBK conceived the study with further participation in crosssectional surveys by JElaC, AA, MAr, AW and MAd. Real-time PCR assays were performed by Hal$\mathrm{S}$ with assistance from JElaC and JRS. Data were tabulated by HAl-S and analysed with the support of MCS and JRS. All authors contributed to the drafting and revision of the manuscript with JRS as guarantor.

Competing interests: None declared.

Funding: HAL-S is in receipt of a PhD Scholarship from the Ministry of Health, Kingdom of Saudi Arabia.

Ethical approval: The study was approved by the Liverpool School of Tropical Medicine and Uganda National Council for Science and Technology. 


\section{Figure legends}

Figure 1. Inset: sketch map of Uganda and study area denoted A. Outline map of the 5 schools inspected. The primary schools of Biiso and Busingiro are located on top of the escarpment whereas Bugoigo, Walakuba and Runga on the lakeshore plain. Once part of Masindi District, the schools are now located within Buliisa District after administrative areas were revised. The northern village of Packwack was where the national control programme against bilharzia and intestinal worms was launched in 2003.

\section{Figure 1}

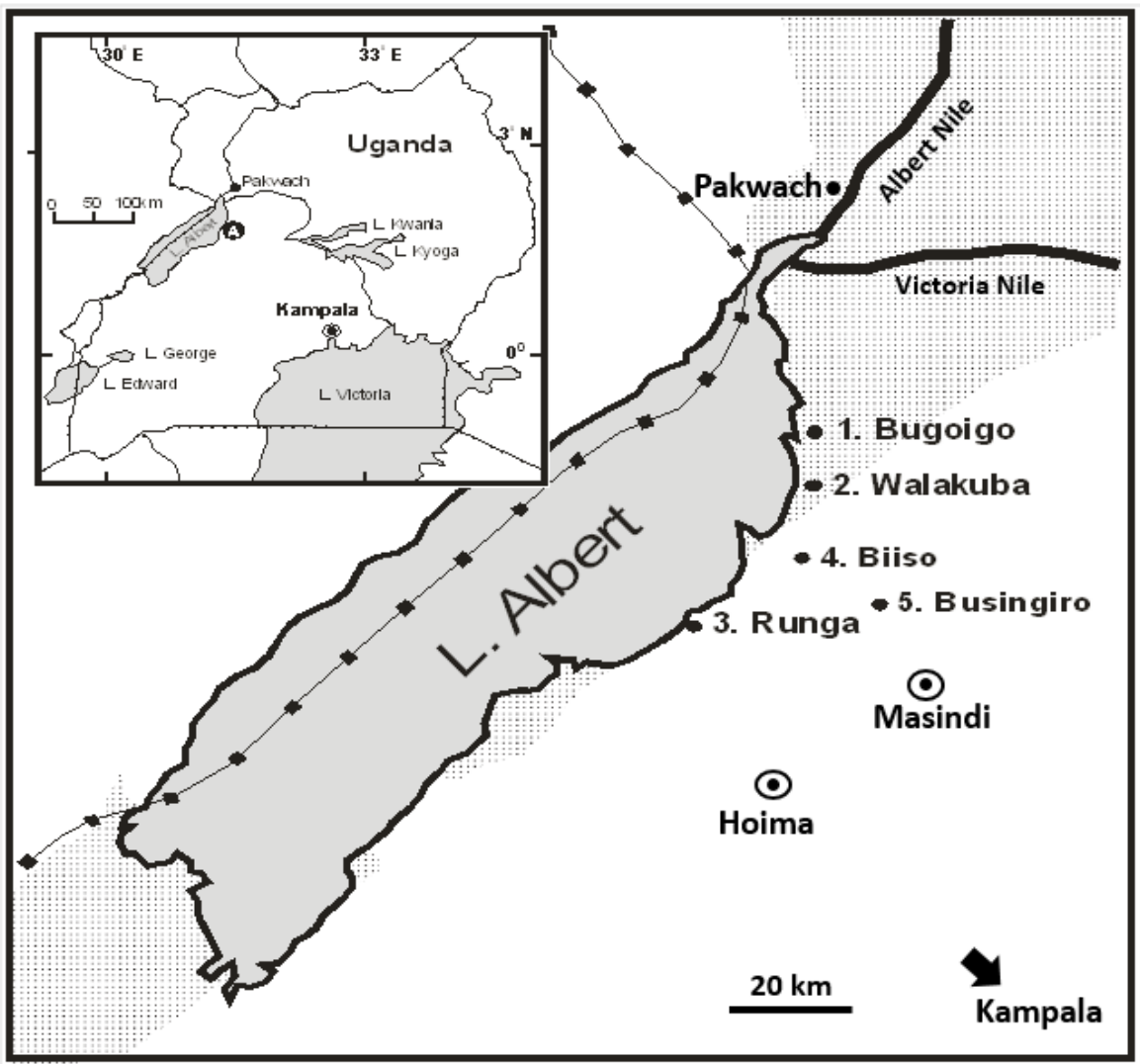


Figure 2. Box plot of haemoglobin levels and heavy infection status with Giardia as measured by realtime PCR.

Figure 2

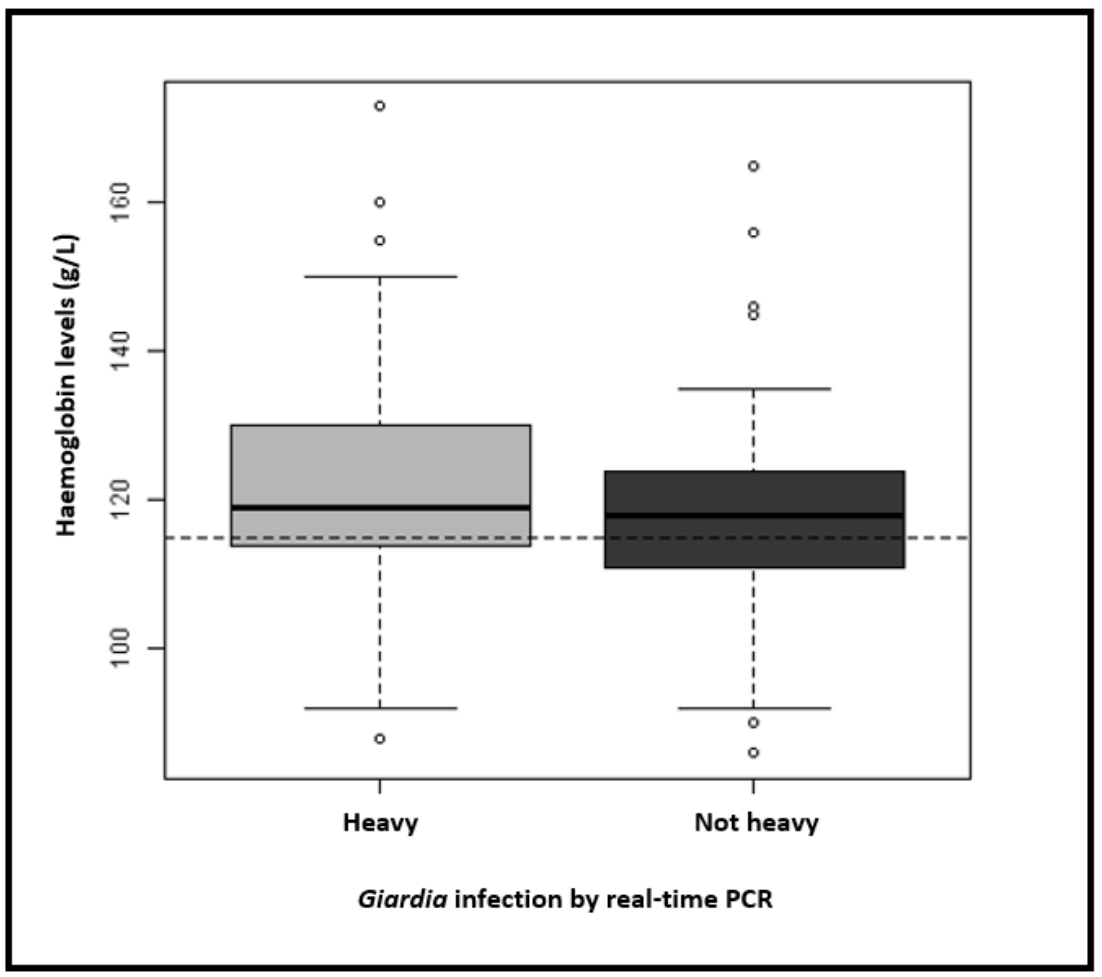




\section{References}

1. Kabatereine NB, Brooker S, Tukahebwa EM, et al.; Epidemiology and geography of Schistosoma mansoni in Uganda: implications for planning control. Tropical Medicine \& International Health 2004;9(3):372-380. doi: 10.1046/j.1365-3156.2003.01176.x.

2. Loewenberg S; Uganda's struggle with schistosomiasis. Lancet 2014;383(9930):1707-1708.

3. Dunne DW, Vennervald BJ, Booth M, et al.; Applied and basic research on the epidemiology, morbidity, and immunology of schistosomiasis in fishing communities on Lake Albert, Uganda. Transactions of the Royal Society of Tropical Medicine and Hygiene 2006;100(3):216-223. doi: 10.1016/j.trstmh.2005.03.016.

4. Stothard JR, Lockyer AE, Kabatereine NB, et al.; Schistosoma bovis in western Uganda. Journal of Helminthology 2004;78(3):281-284. doi: 10.1079/joh2004239.

5. Rowel C, Fred B, Betson M, et al.; Environmental epidemiology of intestinal schistosomiasis in Uganda: population dynamics of Biomphalaria (Gastropoda: Planorbidae) in Lake Albert and Lake Victoria with observations on natural infections with digenetic trematodes. Biomed Research International 2015. doi: 10.1155/2015/717261.

6. de Moira AP, Fulford AJC, Kabatereine NB, et al.; Microgeographical and tribal variations in water contact and Schistosoma mansoni exposure within a Ugandan fishing community. Tropical Medicine \& International Health 2007;12(6):724-735. doi: 10.1111/j.1365-3156.2007.01842.x.

7. Sousa-Figueiredo JC, Oguttu D, Adriko M, et al.; Investigating portable fluorescent microscopy (CyScope $(\mathrm{R})$ ) as an alternative rapid diagnostic test for malaria in children and women of child-bearing age. Malaria Journal 2010;9. doi: 10.1186/1475-2875-9-245.

8. Booth M, Vennervald BJ, Kabatereine NB, et al.; Hepatosplenic morbidity in two neighbouring communities in Uganda with high levels of Schistosoma mansoni infection but very different durations of residence. Transactions of the Royal Society of Tropical Medicine and Hygiene 2004;98(2):125136. doi: 10.1016/s0035-9203(03)00018-x.

9. Wilson S, Vennervald BJ, Dunne DW; Chronic hepatosplenomegaly in African school children: A common but neglected morbidity associated with schistosomiasis and malaria. Plos Neglected Tropical Diseases 2011;5(8). doi: 10.1371/journal.pntd.0001149.

10. Brooker SJ, Pullan RL, Gitonga CW, et al.; Plasmodium-helminth coinfection and its sources of heterogeneity across East Africa. Journal of Infectious Diseases 2012;205(5):841-852. doi: 10.1093/infdis/jir844.

11. Fenwick A, Webster JP, Bosque-Oliva E, et al.; The Schistosomiasis Control Initiative (SCI): rationale, development and implementation from 2002-2008. Parasitology 2009;136(13):1719-1730. doi: $10.1017 / \mathrm{s} 0031182009990400$.

12. Seto EYW, Sousa-Figueiredo JC, Betson M, et al.; Patterns of intestinal schistosomiasis among mothers and young children from Lake Albert, Uganda: water contact and social networks inferred from wearable global positioning system dataloggers. Geospatial Health 2012;7(1):1-13.

13. Bustinduy AL, Luzinda K, Mpoya S, et al.; Case Report: Endomyocardial fibrosis (EMF) in a Ugandan child with advanced hepatosplenic schistosomiasis: Coincidence or connection? American Journal of Tropical Medicine and Hygiene 2014;91(4):798-800. doi: 10.4269/ajtmh.14-0156.

14. Painter JE, Gargano JW, Collier SA, et al.; Giardiasis surveillance-United States, 2011-2012. MMWR Surveill Summ 2015;64(Suppl 3):15-25. 
15. Leder K, Weller P, Weller PF, et al.; http://www.uptodate.com/contents/epidemiology-clinicalmanifestations-and-diagnosis-of-giardiasis.

16. Halliez MC, Buret AG; Extra-intestinal and long term consequences of Giardia duodenalis infections. World Journal of Gastroenterology 2013;19(47):8974.

17. DuPont HL; Giardia: both a harmless commensal and a devastating pathogen. The Journal of Clinical Investigation 2013;123(6):2352.

18. Savioli L, Smith H, Thompson RCA; Giardia and Cryptosporidium join the 'neglected diseases initiative'. Trends in Parasitology 2006;22(5):203-208.

19. Teixeira JC, Heller L, Barreto ML; Giardia duodenalis infection: risk factors for children living in sub-standard settlements in Brazil. Cadernos de Saúde Pública 2007;23(6):1489-1493.

20. Redpath SA, Fonseca NM, Perona-Wright G; Protection and pathology during parasite infection: IL-10 strikes the balance. Parasite Immunology 2014;36(6):233-252. doi: 10.1111/pim.12113.

21. Ankarklev J, Hestvik E, Lebbad M, et al.; Common coinfections of Giardia intestinalis and Helicobacter pylori in non-symptomatic Ugandan children. PLoS Negl Trop Dis 2012;6(8):e1780.

22. Fuhrimann S, Winkler MS, Kabatereine NB, et al.; Risk of intestinal parasitic infections in people with different exposures to wastewater and fecal sludge in Kampala, Uganda: A cross-sectional study. Plos Neglected Tropical Diseases 2016;10(3). doi: 10.1371/journal.pntd.0004469.

23. McElligott JT, Naaktgeboren C, Makuma-Massa H, et al.; Prevalence of intestinal protozoa in communities along the Lake Victoria region of Uganda. International Journal of Infectious Diseases 2013;17(8):E658-E659. doi: 10.1016/j.ijid.2013.03.010.

24. Hogan JN, Miller WA, Cranfield MR, et al.; Giardia in mountain Gorillas (Gorilla beringei beringei), forest buffalo (Syncerus caffer), and domestic cattle in Volcanoes National Park, Rwanda. Journal of Wildlife Diseases 2014;50(1):21-30. doi: 10.7589/2012-09-229.

25. Sak B, Petrzelkova KJ, Kvetonova D, et al.; Diversity of Microsporidia, Cryptosporidium and Giardia in Mountain Gorillas (Gorilla beringei beringei) in Volcanoes National Park, Rwanda. Plos One 2014;9(11). doi: 10.1371/journal.pone.0109751.

26. Balen J, Stothard JR, Kabatereine NB, et al.; Morbidity due to Schistosoma mansoni: an epidemiological assessment of distended abdomen syndrome in Ugandan school children with observations before and 1-year after anthelminthic chemotherapy. Transactions of the Royal Society of Tropical Medicine and Hygiene 2006;100(11):1039-1048. doi: 10.1016/j.trstmh.2005.12.013.

27. Kabatereine NB, Brooker S, Koukounari A, et al.; Impact of a national helminth control programme on infection and morbidity in Ugandan schoolchildren. Bulletin of the World Health Organization 2007;85(2):91-99.

28. Organization $\mathrm{WH}$; Haemoglobin concentrations for the diagnosis of anaemia and assessment of severity. 2011.

29. Verweij JJ, Blangé RA, Templeton K, et al.; Simultaneous detection of Entamoeba histolytica, Giardia lamblia, and Cryptosporidium parvum in fecal samples by using multiplex real-time PCR. Journal of Clinical Microbiology 2004;42(3):1220-1223.

30. Armitage P, Berry G. Statistical Methods in Medical Research: Oxford: Blackwell Scientific Publications., 1994

31. Bustinduy AL, Sousa-Figueiredo JC, Adriko M, et al.; Fecal occult blood and fecal calprotectin as point-of-care markers of intestinal morbidity in Ugandan children with Schistosoma mansoni infection. Plos Neglected Tropical Diseases 2013;7(11). doi: 10.1371/journal.pntd.0002542. 
32. Green HK, Sousa-Figueiredo JC, Basanez M-G, et al.; Anaemia in Ugandan preschool-aged children: the relative contribution of intestinal parasites and malaria. Parasitology 2011;138(12):15341545. doi: 10.1017/s0031182011001016.

33. Grimes JE, Croll D, Harrison WE, et al.; The role of water, sanitation, and hygiene in reducing schistosomiasis: a review. Parasites \& Vectors 2015;8(1):156.

34. Grimes JET, Croll D, Harrison WE, et al.; The relationship between water, sanitation and schistosomiasis: A systematic review and meta-analysis. Plos Neglected Tropical Diseases 2014;8(12). doi: 10.1371/journal.pntd.0003296.

35. Mahdy AM, Lim Y, Surin J, et al.; Risk factors for endemic giardiasis: highlighting the possible association of contaminated water and food. Transactions of the Royal Society of Tropical Medicine and Hygiene 2008;102(5):465-470.

36. Stothard JR, Kabatereine NB, Archer J, et al.; A centenary of Robert T. Leiper's lasting legacy on schistosomiasis and a COUNTDOWN on control of neglected tropical diseases. Parasitology 2016;Epub.

37. Levitz S, Standley CJ, Adriko M, et al.; Environmental epidemiology of intestinal schistosomiasis and genetic diversity of Schistosoma mansoni infections in snails at Bugoigo village, Lake Albert. Acta Tropica 2013;128(2):284-291. doi: 10.1016/j.actatropica.2012.10.003.

38. Bartram J, Cairncross S; Hygiene, sanitation, and water: Forgotten foundations of health. Plos Medicine 2010;7(11). doi: 10.1371/journal.pmed.1000367.

39. Stothard JR, Sousa-Figueiredo JC, Betson M, et al.; Schistosomiasis in African infants and preschool children: let them now be treated! Trends in Parasitology 2013;29(4):197-205. doi: 10.1016/j.pt.2013.02.001.

40. Easton AV, Oliveira RG, O'Connell EM, et al.; Multi-parallel qPCR provides increased sensitivity and diagnostic breadth for gastrointestinal parasites of humans: field-based inferences on the impact of mass deworming. Parasites \& Vectors 2016;9. doi: 10.1186/s13071-016-1314-y.

41. Mejia R, Vicuna Y, Broncano N, et al.; A novel, multi-parallel, real-time polymerase chain reaction approach for eight gastrointestinal parasites' provides improved diagnostic capabilities to resource-limited at-risk populations. American Journal of Tropical Medicine and Hygiene 2013;88(6):1041-1047. doi: 10.4269/ajtmh.12-0726.

42. Schuurman T, Lankamp P, Van Belkum A, et al.; Comparison of microscopy, real-time PCR and a rapid immunoassay for the detection of Giardia lamblia in human stool specimens. Clinical Microbiology and Infection 2007;13(12):1186-1191. 
Table 1. Prevalence of infection by school and across the total of 254 children aged between 5 and 10 years of age.

\begin{tabular}{|c|c|c|c|c|c|c|c|}
\hline \multirow[t]{2}{*}{ School Locations } & & Bugoigo $(n=60)$ & Walukuba $(n=56)$ & Runga ( $n=54)$ & Biso $(n=51)$ & Busingiro $\mid(n=50)$ & Total $(n=271)$ \\
\hline & & $\%$ & $\%$ & $\%$ & $\%$ & $\%$ & $\%$ \\
\hline \multicolumn{8}{|l|}{ Prevalence } \\
\hline \multicolumn{8}{|c|}{ S. mansoni (Kato-Katz) } \\
\hline & Negative & $63.3(38 / 60)$ & $18.0(9 / 50)$ & $13.2(7 / 53)$ & $80.3(41 / 51)$ & $92.0(46 / 50)$ & $53.4(141 / 264)$ \\
\hline & Light & $26.6(16 / 60)$ & $10.0(5 / 50)$ & $13.2(7 / 53)$ & $5.8(3 / 51)$ & $2.0 \quad(1 / 50)$ & $12.1(32 / 264)$ \\
\hline & Moderate & $5.0(3 / 60)$ & $26.0(13 / 50)$ & $11.3(6 / 53)$ & $9.8(5 / 51)$ & $4.0(2 / 50)$ & $10.9(29 / 264)$ \\
\hline & Heavy & $5.0(3 / 60)$ & $46.0(23 / 50)$ & $62.2(33 / 53)$ & $3.9(2 / 51)$ & $2.0(1 / 50)$ & $23.4(62 / 264)$ \\
\hline \multicolumn{8}{|c|}{ Giardia (QUIK $\mathrm{CHEK}^{\mathrm{a}}$ ) } \\
\hline & Negative & $63.0(29 / 46)$ & ND & $54.0(27 / 50)$ & ND & ND & $58.3(56 / 96)$ \\
\hline & Positive & $36.9(17 / 46)$ & ND & $46.0(23 / 50)$ & ND & ND & $41.6(40 / 96)$ \\
\hline \multicolumn{8}{|c|}{ Giardia (TaqMan®) } \\
\hline & Negative & $5.4(3 / 55)$ & $12.0(6 / 50)$ & $5.8(3 / 51)$ & $16.0(8 / 50)$ & $27.0(13 / 48)$ & $12.9(33 / 254)$ \\
\hline & Light & $47.2(26 / 55)$ & $12.0(6 / 50)$ & $1.9(1 / 51)$ & $28.0(14 / 50)$ & $45.8(22 / 48)$ & $27.1(69 / 254)$ \\
\hline & Moderate & $36.3(20 / 55)$ & $54.0(27 / 50)$ & $50.9(26 / 51)$ & $38.0(19 / 50)$ & $22.9(11 / 48)$ & $40.5(103 / 254)$ \\
\hline & Heavy & $10.9(6 / 55)$ & $22.0(11 / 50)$ & $41.1(21 / 51)$ & $18.0(9 / 50)$ & $4.1(2 / 48)$ & $19.2(49 / 254)$ \\
\hline \multicolumn{8}{|l|}{ Malaria (RDTs) } \\
\hline & Negative & $48.2(28 / 58)$ & $64.8(35 / 54)$ & $38.8(21 / 54)$ & $31.3(16 / 51)$ & $34.0(17 / 50)$ & $43.8(117 / 267)$ \\
\hline & Positive & $51.7(30 / 58)$ & $35.1(19 / 54)$ & $61.1(33 / 54)$ & $68.6(35 / 51)$ & $66.0(33 / 50)$ & $56.1(150 / 267)$ \\
\hline \multicolumn{8}{|l|}{ Co-infection* } \\
\hline & Negative & $85.0(51 / 60)$ & $80.0(45 / 56)$ & $51.8(28 / 54)$ & $86.2(44 / 51)$ & $98.0(49 / 50)$ & $80.0(217 / 271)$ \\
\hline & Positive & $15.0(9 / 60)$ & $19.6(11 / 56)$ & $48.1(26 / 54)$ & $13.7(7 / 51)$ & $2.0(1 / 50)$ & $19.9(54 / 271)$ \\
\hline \multicolumn{8}{|l|}{ Anaemia } \\
\hline & $(<115 \mathrm{Hb})$ & & & & & & \\
\hline & & $36.6(22 / 60)$ & $33.9(19 / 56)$ & $44.4(24 / 54)$ & $5.8(3 / 51)$ & ND & $30.7(68 / 221)$ \\
\hline
\end{tabular}


Table 2. Adjusted risk factors associated with heavy Giardia infection by real-time PCR

\begin{tabular}{|c|c|c|c|c|}
\hline Heavy Giardia infection* & Positive $(n=49)$ & Negative $(n=205)$ & OR & {$[95 \% \mathrm{CI}]$} \\
\hline & $\%$ & $\%$ & & \\
\hline School & 10.9 & 89.1 & - & - \\
\hline Runga & 41.2 & 58.8 & 5.7 & {$[2.2,17.0]$} \\
\hline Walukuba & 22.0 & 78.0 & 2.3 & {$[0.8,7.2]$} \\
\hline Biiso & 18.0 & 82.0 & 1.8 & {$[0.6,5.7]$} \\
\hline Busingiro & 4.2 & 95.8 & 0.4 & {$[0.1,1.6]$} \\
\hline \multicolumn{5}{|l|}{ Age group } \\
\hline $5-6$ & 19.3 & 80.7 & - & - \\
\hline $7-8$ & 20.8 & 79.2 & 1.1 & {$[0.56,2.1]$} \\
\hline $9-10$ & 15.4 & 84.6 & 0.7 & {$[0.26,1.9]$} \\
\hline \multicolumn{5}{|l|}{ Gender } \\
\hline Female & 15.9 & 84.0 & - & - \\
\hline Male & 23.0 & 77.0 & 1.5 & {$[0.84,2.9]$} \\
\hline \multicolumn{5}{|c|}{ Faecal occult blood (FOB) } \\
\hline Negative & 17.7 & 82.3 & - & - \\
\hline Positive & 32.1 & 67.8 & 2.2 & {$[0.89,5.1]$} \\
\hline \multicolumn{5}{|c|}{ Kato-Katz intensity } \\
\hline Negative & 11.2 & 88.8 & - & - \\
\hline Light & 33.3 & 66.6 & 3.9 & {$[1.54,10.0]$} \\
\hline Moderate & 26.9 & 73.0 & 2.9 & {$[1.01,7.9]$} \\
\hline Heavy & 28.1 & 71.9 & 3.1 & {$[1.41,6.8]$} \\
\hline \multicolumn{5}{|l|}{ Anaemia $^{+}$} \\
\hline Negative & 16.0 & 84.0 & - & - \\
\hline Positive & 30.0 & 70.0 & 2.2 & {$[1.14,4.3]$} \\
\hline
\end{tabular}

* Heavy Giardia infection categorised by real-time PCR (Ct value $\leq 19)$ versus negative, light and moderate infection + Hb less than $115 \mathrm{~g} / \mathrm{L}$ 